FORAMS 2006

\title{
Rethinking the test: Functional and evolutionary implications
}

\author{
S.S. Bowser ${ }^{1}$; A. Habura ${ }^{1}$; J.M. Bernhard ${ }^{2} \&$ J. Pawlowski ${ }^{3}$ \\ ${ }^{1}$ Wadsworth Center, NY State Department of Health, Albany, NY 12201, U.S.A. \\ bowser@wadsworth.org \\ ${ }^{2}$ Woods Hole Oceanographic Institution, Woods Hole, MA 02543 U.S.A. \\ ${ }^{3}$ University of Geneva, 1211 Genève 4, CH, Switzerland
}

Foraminiferal tests are often regarded as simple protective coverings. Other test functions have been proposed, e.g., serving as ballast to resist hydrodynamic forces, or to help "guide" the development of pseudopodia. The function of test ornamentations is less obvious. Certain features, such as apertural teeth, may help disaggregate food particles as they pass along their surfaces, but the function of other ornamentation remains elusive.

Our recent work with "primitive" unilocular foraminiferans, involving 3D microscopy and nanofabricated substrates, has revealed a potentially unifying concept regarding test function and evolution. The ability of reticulopodia to extend over great distances (due, in part, to the evolution of their unique tubulin storage polymorph) enables forams to employ elevated substrates to capture suspended particles with enhanced efficiency. We view this basic pseudopodial function as a powerful driving force for the evolution of the test and many of its features, starting with those associated with "simple" agglutinated forams (e.g., Hemisphaerammina) and progressing toward the most complex topologies, e.g., as seen in Homotrema.

Supported by NSF grants DEB0445181 and ANT0440769. 